\title{
Dispatches from the land of the morning calm: special issue papers from the 18th International Symposium on the Biology of Actinomycetes
}

\author{
Paul A. Hoskisson • Gilles P. van Wezel
}

Published online: 9 April 2018

(C) Springer International Publishing AG, part of Springer Nature 2018

\begin{abstract}
Actinobacteria can be found on every continent, from the deepest oceans to the highest mountains, and are significant members of the microbiota of almost every niche that has been explored. Moreover, they are a phylum of medically, agriculturally and industrially significant bacteria, with huge diversity in form and function. Actinobacteria can be regarded as nature's medicine makers, with plants, animals and insects profiting from the chemical protection they offer. Since its beginnings in 1968 in the German city of Jena, and now in its 50th year, the International Symposium on the Biology of Actinomycetes (ISBA) has become more than just a conference. ISBA is a community. A group of scientists from across the globe that get together every 2-3 years to celebrate the remarkable biology of these incredible organisms. An exciting generalist meeting that still thrives in an era where specialisation is the trend. On the 23-27th May 2017, ISBA18 convened on the beautiful Island of Jeju, just off the south coast of Korea-the land of the morning calm. Expertly
\end{abstract}

P. A. Hoskisson ( $\square)$

Strathclyde Institute of Pharmacy and Biomedical

Science, University of Strathclyde, 161 Cathedral Street,

Glasgow G4 0RE, UK

e-mail: Paul.hoskisson@strath.ac.uk

G. P. van Wezel

Molecular Biotechnology, Institute of Biology, Leiden

University, Sylviusweg 72, 2333 BE Leiden, The

Netherlands organised by Professor Jung-Hye Roe and her team, the International ISBA organising committee pulled together a wonderful series of sessions reflecting the diverse biology of Actinobacteria.

The programme was divided into 13 symposia, three workshops, with nine plenary lectures and a special lecture by Professor Satoshi Ōmura - the 2015 Nobel laureate in Physiology and Medicine (alongside Professor William Campbell) for the discovery of avermectin, produced by Streptomyces avermitilis. The ISBA programme represented the diversity of the biology of Actinobacteria covering cell biology, chemical biology, corynebacteria, developmental biology, ecology, gene regulation, genetics, natural products and their biosynthesis, physiology, mycobacteria, and systematics and evolution.

In this special issue of Antonie van Leeuwenhoek, we have gathered together a range of papers from the meeting that reflect the diversity of topics covered during ISBA18. The papers presented in this issue encompass antibiotic induction, regulation and metabolic engineering, cell division and cell-wall biosynthesis, comparative genomics evolution of phage-shock proteins, plantStreptomyces interactions and phytotoxin production, selective isolation and characterisation of novel species.

We hope that you, the readers, enjoy reading the papers as much as we enjoyed editing them and bringing this issue together. We also hope that they will provide a taster and encourage attendance at the 19th ISBA, which will be held in Toronto, Canada in 2020. 